13 Novelline RA, Baltarovich $\mathrm{OH}$, Athanasoulis CA, et al. The clinical course of patients with suspected pulmonary embolism and a negative arteriogram. Radiology 1978;126:561-7.

14 Dalen JE, Brooks HL, Johnson LW, et al. Pulmonary angiography in acute pulmonary embolism: indications, techniques and results in 367 patients. Am Heart f 1971;81:175-85.

15 Tentalman MR, Hoffer PB, Heck LL, Kunzmann A, Gottschalk A. Perfusion scans in normal volunteers. Radiology 1973:106:593-4.

16 McBride K, La Morte WW, Menzoian JO. Can ventilation-perfusion scans accurately diagnose acute pulmonary embolism? Arch Surg 1986;121:754-7.

17 (iutnk LM. Pulmonary embolus with a normal ventilation prrfusion lung scan. $S$ D g Mid 1983;36:17-9.

18 McNeil BJ. A diagnostic strategy using ventilation-perfusion studies in patients suspect for pulmonary embolism. F Nucl Med 1976;17:613-6.

19 Frankez N, Coleman RE, Pryor DB, Sostman HD, Ravin CE. Utilisation of lung scans by clinicians. f Nucl Med 1986;27:366-9.

\section{Child abuse or copper deficiency? A radiological view}

Copper deficiency has been a recognised cause of hypochromic, microcytic anaemia and neutropenia in infants for

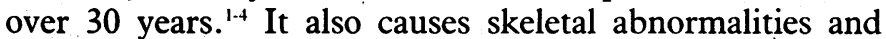
fractures, and recently copper deficiency has been offered to the courts (and given wide publicity) as an explanation of the radiological findings in children whose parents have been charged with abuse. The case of one such child with multiple rib, long bone, and metaphysical fractures was recently heard by the Court of Appeal. In dismissing the appeal the Lord Chief Justice rejected the defence's evidence on copper deficiency and suggested that it actually strengthened the prosecution case.

Should copper deficiency be considered in the differential diagnosis of non-accidental injury? The skeletal manifestations of copper deficiency occur late ${ }^{+}$and comprise retardation of bone age, osteoporosis (which is often severe), metaphyseal cupping, increased density of the zone of provisional calcification, and metaphyseal sickle shaped spurs. These changes are distributed symmetrically throughout the skeleton. ${ }^{5}$ Copper deficiency is rare-only about 100 cases have been reported-and fractures caused by copper deficiency are even rarer: there have been 16 documented cases, and only five in term infants. ${ }^{35-7}$ Full term infants are born with high body stores of copper that are sufficient for at least the first six months of life. Modern British infant feeding formulas containing $40 \mu \mathrm{g}$ copper per $100 \mathrm{ml}$ are not associated with copper deficiency in term infants, and no breast fed infant has ever developed copper deficiency. The five full term infants with fractures were all having an abnormal diet or total parenteral nutrition. Rib fractures have been recorded only in premature infants, and skull fractures have never been described. All the children with fractures had obviously abnormal bones.

Metaphyseal fractures are highly suggestive of nonaccidental injury and are the most valuable single diagnostic radiographic feature. ${ }^{8}$ They are undoubtedly traumatic: some parents admit to injuring their child, and similar lesions are seen in newborn infants who have suffered a traumatic breech delivery. The new bone formation that accompanies fracture healing is often not present with intra-articular fractures, ${ }^{9}$ and the fractures themselves often do not produce local pain, swelling, and heat. ${ }^{810}$ Those who are unfamiliar with this picture may discount a traumatic origin and ascribe the radiological signs to another cause of metaphyseal abnormalities-such as copper deficiency.

The differentiation of metaphyseal abnormalities caused by copper deficiency from metaphyseal fractures caused by child abuse and from normal developmental variants, such as cupping of the anterior ends of ribs and metaphyseal breaking, is not difficult for the experienced. BennaniSmires $e t a l^{7}$ described a term infant with multiple metaphyseal fractures caused by copper deficiency that mimicked non-accidental injury, pointing out that it might be possible to confuse the two conditions. The fractures were, however, symmetrical, and other signs of copper deficiency-that is, osteoporosis, metaphyseal cupping, and sickle shaped spurs -were also present. The presence of otherwise normal bones with a normal bone age excludes copper deficiency of a severity sufficient to cause fractures. When other features of copper deficiency (low serum copper and caeruloplasmin concentrations, neutropenia, and anaemia) and predisposing factors (prematurity, total parenteral nutrition, or copper deficient milk) are also absent we can be even more confident.

STEPHEN CHAPMAN

Consultant Paediatric Radiologist,

Children's Hospital

Birmingham B16 8ET

Sturgeon P, Brubaker C. Copper deficiency in infants. Am f Dis Child 1956:92:254-65.

2 Schubert WK Lahey ME Copper and protein depetion complicating hypoferric anaemia of infancy. Pediatrics 1959;24:710-33.

3 Cordano A, Baertl JM, Graham GG. Copper deficiency in infancy. Pediatrics 1964:34:324-36.

4 Graham GG, Cordano A. Copper depletion and deficiency in the malnourished infant. Fohns Hopkins Med F 1969;124:139-50.

5 Grünebaum $M$, Horodniceanu $C$, Steinherz R. The radiographic manifestations of bone changes in copper deficiency. Pediatr Radiol 1980;9:101-4.

6 Cordano A, Graham GG. Copper deficiency complicating severe chronic intestinal malabsorption. Pediatrics 1966;38:596-604.

7 Bennani-Smires C, Medina J, Young LW. Infantile nutritional copper deficiency. Am 7 Dis Child 1980;134:1155-6.

8 Caffev J. The first annual Neuhauser presidential address of the Society for Paediatric Radiology. The parent-infant stress syndrome (Caffey-Kempe syndrome), (battered babe syndrome Am 7 Roentgenol 1977;114:217-29.

9 Cameron JM, Rae LJ. Atlas of the battered child syndrome. Edinburgh: Churchill Livingstone, 1975:34.

10 Merten DF, Radkowski MA, Leonidas JC. The abused child: a radiological reappraisal. Radiologv 1983;146:377-81

\section{Assessment before prostatectomy}

Prostatectomy is best performed by the transurethral method. Since most patients will be over 60 preoperative cardiopulmonary assessment is required, and in some cases spinal rather than general anaesthesia may be essential. Preoperative intravenous urography used to be performed routinely, but this policy has been questioned. ${ }^{1}$ Plain abdominal radiography and ultrasonography may give the same information more easily and cheaply. ${ }^{2}$ Others have concluded, however, that preprostatectomy urography "remains a sound principle of good urological care." 3

Urography may show an intravesical prostatic impression, but prostatic size bears no relation to the symptoms or degree of bladder outlet obstruction. Prostatic size or malignant infiltration are in any case better shown by transrectal ultrasonography or computed tomography. ${ }^{45}$ Nor does the unmodified urogram give quantifiable data on total or split renal function; these require additional clearance studies and radionuclide techniques. ${ }^{67}$ Dilatation of the upper urinary tract in high pressure chronic retention or ureteric invasion by prostatic cancer will be apparent, but the former condition can be diagnosed on clinical criteria ${ }^{8}$ and the latter condition will be shown by histological examination. Showing dilatation preoperatively is unlikely to affect primary management. An empty bladder on urography does not exclude obstruction- 